\title{
BMJ Global Health Secular trends in the prevalence of female genital mutilation/cutting among girls: a systematic analysis
}

\author{
Ngianga-Bakwin Kandala, ${ }^{1,2}$ Martinsixtus C Ezejimofor, ${ }^{1,3}$ Olalekan A Uthman, ${ }^{4}$ \\ Paul Komba ${ }^{1}$
}

To cite: Kandala N-B, Ezejimofor MC, Uthman OA, et al. Secular trends in the prevalence of female genital mutilation/cutting among girls: a systematic analysis. BMJ Glob Health 2018;3:e000549. doi:10.1136/ bmjgh-2017-000549

Handling editor Seye Abimbola

- Additional material is published online only. To view please visit the journal online (http://dx.doi.org/10.1136/ bmjgh-2017-000549).

Received 2 October 2017 Revised 21 June 2018 Accepted 13 July 2018

Check for updates

C Author(s) (or their employer(s)) 2018. Re-use permitted under CC BY-NC. No commercial re-use. See rights and permissions. Published by BMJ.

For numbered affiliations see end of article.

\section{Correspondence to}

Professor Ngianga-Bakwin Kandala;

ngianga-bakwin.kandala@ northumbria.ac.uk

\begin{abstract}
Background Current evidence on the decline in the prevalence of female genital mutilation or cutting $(\mathrm{FGM} / \mathrm{C})$ has been lacking worldwide. This study analyses the prevalence estimates and secular trends in $\mathrm{FGM} / \mathrm{C}$ over sustained periods (ie, 1990-2017). Its aim is to provide analytical evidence on the changing prevalence of $\mathrm{FGM} / \mathrm{C}$ over time among girls aged $0-14$ years and examine geographical variations in low-income and middle-income countries.
\end{abstract}

Methods Analysis on the shift in prevalence of $\mathrm{FGM} / \mathrm{C}$ was undertaken using the Demographic Health Survey (DHS) and Multiple Indicator Cluster Survey (MICS) data sets from Africa and Middle East. A random-effects model was used to derive overall prevalence estimates. Using Poisson regression models, we conducted time trends analyses on the FGM/C prevalence estimates between 1990 and 2017. Findings We included 90 DHS and MICS data sets for 208195 children (0-14 years) from 29 countries spread across Africa and two countries in Western Asia. The prevalence of $F G M / C$ among children varied greatly between countries and regions and also within countries over the survey periods. The percentage decline in the prevalence of $\mathrm{FGM} / \mathrm{C}$ among children aged $0-14$ years old was highest in East Africa, followed by North and West Africa. The prevalence decreased from $71.4 \%$ in 1995 to 8.0\% in 2016 in East Africa. In North Africa, the prevalence decreased from $57.7 \%$ in 1990 to $14.1 \%$ in 2015. In West Africa, the prevalence decreased from $73.6 \%$ in 1996 to $25.4 \%$ in 2017. The results of the trend analysis showed a significant shift downwards in the prevalence of FGM/C among children aged $0-14$ years in such regions and subregions of East Africa, North Africa and West Africa. East Africa has experienced a much faster decrease in the prevalence of the practice (trend $=-7.3 \%, 95 \% \mathrm{Cl}-7.5 \%$ to $-7.1 \%$ ) per year from 1995 to 2014 . By contrast, the decline in prevalence has been much slower in North Africa (trend $=-4.4 \%, 95 \% \mathrm{Cl}-4.5 \%$ to $-4.3 \%$ ) and West Africa (trend $=-3.0 \%, 95 \% \mathrm{Cl}-3.1 \%$ to $-2.9 \%$ ).

Conclusion The prevalence of FGM/C among children aged $0-14$ years varied greatly between countries and regions and also within countries over the survey periods. There is evidence of huge and significant decline in the prevalence of $\mathrm{FGM} / \mathrm{C}$ among children across countries and regions. There is a need to sustain comprehensive intervention efforts and further targeted efforts in countries and regions still showing high prevalence of $\mathrm{FGM} / \mathrm{C}$ among children, where the practice is still pervasive.
Key questions

What is already known?

- Female genital mutilation or cutting (FGM/C) is highly concentrated in many low-income and middle-income countries (LMICs), particularly in Africa and Western Asia.

- The practice is viewed as a child abuse and a gross violation of children's and women's human rights, and is deemed unlawful by many countries and condemned by many organisations.

- It has devastating health consequences especially in terms of sexual, childbirth and mental health.

\section{What are the new findings?}

- The prevalence of FGM/C among children varied greatly between countries and regions and also within countries over the survey periods.

- We found evidence of significant decline in the prevalence of FGM/C in the last three decades among children aged 0-14 years in most of the countries and regions, particularly in East, North and West Africa.

- We show that the picture looks different in Western Asia, where the practice remains and affects the same age group.

What do the new findings imply?

- Evidence-based policies targeting socioeconomic and cultural support for children at risk of $F G M / C$ in LMICs should be pursued vigorously.

- Appropriate research design, data collection and interventions containing religious and culturally sensitive elements remain an important public health policy priority.

\section{INTRODUCTION}

Recent estimates show that more than 200 million women and children around the world have undergone female genital mutilation and cutting (FGM/C).${ }^{12}$ All the available data clearly refer to Africa and some Middle Eastern regions (including Iraq and Yemen) as areas where the practice is particularly most prevalent. Further findings from recent global research revealed the existence 
of such a practice in India, Indonesia, Israel, Malaysia, Thailand and the United Arab Emirates. Likewise, data from censuses and household and hospital records indicate that FGM/C constitutes a massive global health challenge in the sense that the high burden of FGM/C is clearly not confined to African and Middle Eastern countries, but extends to Europe and North and South America, especially as a result of migration. ${ }^{2-6}$ Incidents of FGM/C in the Western world are reported particularly from among asylum seekers and immigrants who have moved from regions where FGM/C is practised in order to settle in developed countries. ${ }^{3-6}$ Those who live in Africa have been affected by the practice as a result of socioeconomic and cultural issues. Thus, there is an emerging consensus that more than three million children in Africa are now at risk each year. ${ }^{7}$ In the present paper, we first offer an analytical picture of the estimates on the prevalence of FGM/C and identify secular trends limiting the study population to young girls aged 0-14 years in low-income and middle-income countries (LMICs).

The ultimate aim of this study is to inform decision-making processes and influence policy responses and public health intervention across many geographical regions and countries sharing the same socioeconomic and cultural backgrounds (such as unemployment level, level of education, and religion and ethnicity). The focus on these backgrounds is accounted for by a large number of selected regions in which well-tailored intervention programmes may be necessary to combat the practice.

Accurate, up-to-date information on the prevalence of FGM/C among children is necessary for the development of national and international health policies for prevention of this practice, and would allow international public health policy-makers to assign sufficient priority and resources to its prevention. Although there are existing systematic reviews and reports on current prevalence estimates of $\mathrm{FGM} / \mathrm{C}$ emanating from most international agencies, ${ }^{8-14}$ there are no pooled analyses of nationally representative survey data to examine the burden of FGM/C among children. Children aged 0-14 years were considered in this review partly because we wanted to understand whether the years-long campaigns on FGM/C among mothers have an impact on the reduction in the prevalence among their children, as children are relatively too young to understand what is best for themselves, compared with their adult women counterparts who, on personal, cultural and socioeconomic grounds, may engage in FGM/C. To fill this research gap, we therefore systematically gathered all survey data sets to assess (1) the contemporary prevalence estimates of FGM/C among children aged 0-14 years; (2) whether there is significant downward trend in the prevalence estimates or not; and (3) whether the burden of FGM/C among children varies across different geographical regions.

\section{METHODS}

\section{Study design and data}

We used data from the Demographic Health Survey (DHS) as developed by ICF International and the Multiple Indicator Cluster Survey (MICS) directed by Unicef. ICF International and Unicef provide technical assistance to countries conducting these national surveys. The two surveys are highly comparable and the technical teams developing and supporting them are in close collaboration. Both DHS and MICS surveys provide national representative data of households and estimates of adult women and children. This study examines the secular trends in the prevalence of $\mathrm{FGM} / \mathrm{C}$, focusing on countries where DHS/MICS data are available and on regions which significantly contribute to the global prevalence in FGM/C. Evidence suggests that international response has targeted such countries on account of the high prevalence observed in FGM/C practice or based on the number of women and girls at risk. This is the case despite evidence that prevalence may be low in those regions. Among other things, the DHS and MICS survey data sets give details about the health and wellbeing of children as well as women in countries affected by FGM/C practices. The surveys used a two-stage cluster and probability sampling design, with oversampling of certain categories of respondents. In the first stage, 'clusters' were selected from larger regional units within countries using sample weights techniques to obtain nationally representative estimates of indicators. Subsequently, the second stage of sampling, which involved the systematic sampling of households from the selected enumeration areas, was carried out. Data collection procedures and response rates for all DHS and MICS surveys were all published in each survey report.

The data sets on FGM/C are available in 29 countries spread across five United Nations subregions. Based on nationally representative samples of women and children, these surveys produce data that make it possible to calculate both the FGM/C prevalence and secular trends at both the national and subregional levels. In many of the targeted countries, more recent surveys have been produced. ${ }^{15-18}$ In order to provide an accurate and reliable estimate of the current FGM/C practices in these countries and regions, we searched the DHS and MICS databases (without restriction on language or date of publication) to look for FGM/C data on women and their daughters or children.

\section{Statistical analysis}

\section{Meta-analysis of FGM/C prevalence estimates}

Apparent prevalence estimates were computed using the total reported number of children who have undergone $\mathrm{FGM} / \mathrm{C}$ in each country. The overall prevalence of FGM/C was pooled and compared by proportion across countries and regions using a meta-analysis technique. Before making such a move, we used the Freeman-Tukey variant of the arcsine square root transformed proportion suitable for pooling. ${ }^{19}$ This was necessary to stabilise 
the raw proportions of children who have undergone FGM/C from each of the included data. ${ }^{20}$ Thereafter, the DerSimonian and Laird random-effects model was used to summarise the data. ${ }^{21}$

The logit effect size for the prevalence of FGM/C, its $\mathrm{SE}$ and the inverse variance weight are given below:

$$
\begin{gathered}
E S_{i}=\log _{e}\left[\frac{p}{1-p}\right] \\
S E_{i}=\sqrt{\frac{1}{n p}+\frac{1}{n(1-p)}} \\
\mathrm{W}_{\mathrm{i}}=\frac{1}{\mathrm{SEi}^{2}}=\mathrm{np}(1-\mathrm{p})
\end{gathered}
$$

where $p$ represents the proportion (percentage) of children who have undergone $\mathrm{FGM} / \mathrm{C}$, and $n$ is the total number of children who have undergone the practice in the sample surveyed. The final pooled logit results and 95\% CIs were transformed back into proportion for ease of interpretation using the following:

$$
P=\frac{e^{\text {Logit }}}{e^{\text {Logit }+1}}
$$

To assess the variation percentage across surveys, we inspected the forest plot and used the $\chi^{2}$ test and the $\mathrm{I}^{2}$ statistics. ${ }^{22}$ The result was presented as a forest plot with 95\% CIs expressed in percentage. Study-level influence on the estimated FGM/C prevalence was also evaluated using study-level characteristics such as survey year, survey country, survey period and the type of survey (DHS/MICS) in a univariate and multivariate meta-regression. We used a significance level of 0.05 for $p$ values in all statistical analyses. The bulk of data analysis was conducted using Stata V.14 for Windows. This study was conducted and reported in line with the Meta-analysis of Observational Studies in Epidemiology guideline. ${ }^{23}$

\section{Secular trend analysis}

Using Poisson regression models, we conducted time trends analyses on the $\mathrm{FGM} / \mathrm{C}$ prevalence estimates between 1990 and 2017. Regression analyses were conducted using annual data on prevalence, with girls who have been mutilated as the outcome and the survey calendar year as the predictor. This method allows for estimation of time trends across individual calendar years to obtain the average annual percentage change (AAPC), depending on whether the rate of change over the previous year is constant. ${ }^{24}$ The Poisson regression procedure fits a model of the following form:

$$
\log \left(\text { Cases }_{y}\right)=b_{0}+b_{1} y+\log (\text { sample size })
$$

where 'cases' equals the number of $\mathrm{FGM} / \mathrm{C}$ cases reported per year, 'log' is the natural $\log , \mathrm{b}_{0}$ is the intercept, $b_{1}$ is the trend and $y$ is the year. In the equation, each year is represented by $0,1,2 \ldots \ldots 14$ (where year 0 is 1990, year 1 is 1991 and so on until 2017). The log of 'sample size' was subsequently entered as the offset. The AAPC was calculated using the following formula:

$$
A A P C=\left(e b_{1}-1\right) \times 100
$$

We also chose to meta-estimate one temporal trend from all the studies, accounting for correlations among multiple time intervals within studies. ${ }^{25}$ This indicates that the number of time points for which FCM/C was estimated varied across studies, and some of these included only one time point.

\section{RESULTS}

\section{Description of included survey data sets}

The countries, year of data collection and the survey characteristics are listed in table 1 . The surveys were conducted between 1990 and 2017. This analysis included 90 DHS and MICS data sets for 208195 children (0-14 years) from 29 countries spread across Africa and two countries in Western Asia. Most of the surveys were DHS $(n=55)$ and 35 were MICS. Most of the surveys were from West Africa $(n=54)$, followed by East Africa $(n=17)$, North Africa $(n=10)$, Central Africa $(n=6)$ and Western Asia ( $n=3)$ (figure 1). The highest numbers of surveys were conducted in Nigeria $(n=7)$, Senegal $(n=7)$ and Mali $(\mathrm{n}=6)$.

\section{Variations in prevalence of FGM/C among children by country and geographical regions}

The prevalence of FGM/C among children and the $95 \%$ CIs from individual countries with a pooled estimate are shown in online supplementary figure 1 for Central Africa, online supplementary figure 2 for East Africa, online supplementary figure 3 for North Africa, online supplementary figure 4 for West Africa and online supplementary figure 5 for Western Asia, and are summarised in table 1. In Central Africa, the FGM/C 'annualized year average' was highest for Chad (13.9\%), followed by Central Africa Republic (3.0\%) and Cameroon (0.7\%). The FGM/C 'annualized year average' ranged from $2.0 \%$ (Kenya) to $67.0 \%$ (Eritrea) in East Africa; from 28.4\% (Egypt) to $41.9 \%$ (Sudan) in North Africa.

\section{Secular trend in the prevalence of FGM/C among children aged $\mathbf{0}-14$ years}

Table 2 and figure 2 show the trends in the prevalence of FGM/C among children within the $0-14$ age range who have been subjected to FGM/C. The percentage decline in the prevalence of FGM/C among children aged 0-14 years old was highest in East Africa, followed by North and West Africa. The prevalence decreased from $71.4 \%$ in 1995 to $8.0 \%$ in 2016 in East Africa. In North Africa, the percentage decreased from $57.7 \%$ in 1990 to $14.1 \%$ in 2015. In West Africa, the prevalence decreased from $73.6 \%$ in 1996 to $25.4 \%$ in 2017 . This is to be contrasted with the picture in Western Asia, where the percentage increased only by $1.0 \%$ in 1997 and $15.9 \%$ in 2013 .

The results of the trend analysis showed a significant shift downwards in the prevalence of FGM/C among children aged 0-14 years in such regions and subregions of East Africa, North Africa and West Africa. East Africa has experienced a much faster decrease in the prevalence of the practice (trend $=-7.3 \%, 95 \%$ CI $-7.5 \%$ to $-7.1 \%$ ) 
Table 1 DHS/MICS data sets on female genital mutilation or cutting among children (0-14 years) across countries and regions

\begin{tabular}{|c|c|c|c|c|c|}
\hline Region & Country & Survey (n) & Survey period & Sample size & $\begin{array}{l}\text { Annualised year average } \\
(\%)\end{array}$ \\
\hline Central Africa & Chad & 3 & 2004-2015 & 34139 & $13.91(9.60-18.86)$ \\
\hline Central Africa & Central African Republic & 2 & $2006-2010$ & 24219 & $3.02(0.00-11.20)$ \\
\hline Central Africa & Cameroon & 1 & 2004 & 2975 & $0.71(0.43-1.04)$ \\
\hline East Africa & Tanzania & 4 & 1996-2016 & 28718 & $3.17(0.78-7.10)$ \\
\hline East Africa & Somalia & 1 & 2006 & 3716 & 45.99 (44.39-47.59) \\
\hline East Africa & Somalia north-east & 1 & 2011 & 5813 & $30.60(29.43-31.79)$ \\
\hline East Africa & Ethiopia & 3 & 2000-2016 & 22885 & $34.12(15.12-56.26)$ \\
\hline East Africa & Kenya & 4 & 1998-2014 & 18917 & $10.42(2.52-22.79)$ \\
\hline East Africa & Djibouti & 1 & 2006 & 1923 & $48.52(46.29-50.75)$ \\
\hline East Africa & Somaliland & 1 & 2011 & 5729 & $27.70(26.55-28.87)$ \\
\hline East Africa & Eritrea & 2 & 1995-2002 & 6609 & $67.01(58.02-75.41)$ \\
\hline North Africa & Sudan & 3 & 1990-2014 & 41131 & $41.90(30.88-53.36)$ \\
\hline North Africa & Egypt & 7 & 1995-2015 & 85036 & $28.40(16.41-42.18)$ \\
\hline West Africa & Burkina Faso & 4 & 1999-2010 & 33021 & $28.00(15.16-43.01)$ \\
\hline West Africa & Guinea & 4 & 1999-2016 & 26576 & $50.35(44.75-55.95)$ \\
\hline West Africa & Ghana & 1 & 2011 & 8276 & $0.40(0.27-0.55)$ \\
\hline West Africa & Benin & 4 & 2001-2014 & 34399 & $1.80(0.25-4.68)$ \\
\hline West Africa & Senegal & 7 & 2005-2016 & 37087 & $12.96(8.63-18.03)$ \\
\hline West Africa & Niger & 2 & 1998-2006 & 7521 & $5.67(0.00-25.15)$ \\
\hline West Africa & Guinea-Bissau & 3 & $2006-2016$ & 23414 & $34.29(28.63-40.19)$ \\
\hline West Africa & Mauritania & 4 & 2001-2015 & 34100 & $61.20(53.61-68.53)$ \\
\hline West Africa & Sierra Leone & 3 & 2006-2010 & 24268 & $24.67(8.87-45.18)$ \\
\hline West Africa & Mali & 6 & $1996-2015$ & 67404 & $72.59(69.98-75.13)$ \\
\hline West Africa & Togo & 3 & 2006-2014 & 16777 & $0.53(0.21-0.97)$ \\
\hline West Africa & Cote d'Ivoire & 4 & 1999-2016 & 19837 & $13.61(9.25-18.65)$ \\
\hline West Africa & Gambia & 2 & $2006-2010$ & 21972 & $53.43(32.14-74.08)$ \\
\hline West Africa & Nigeria & 7 & 1999-2017 & 104030 & $18.83(14.66-23.39)$ \\
\hline Western Asia & Yemen & 2 & $1997-2013$ & 16037 & $6.31(0.00-28.23)$ \\
\hline Western Asia & Iraq & 1 & 2011 & 8759 & $21.00(20.15-21.85)$ \\
\hline
\end{tabular}

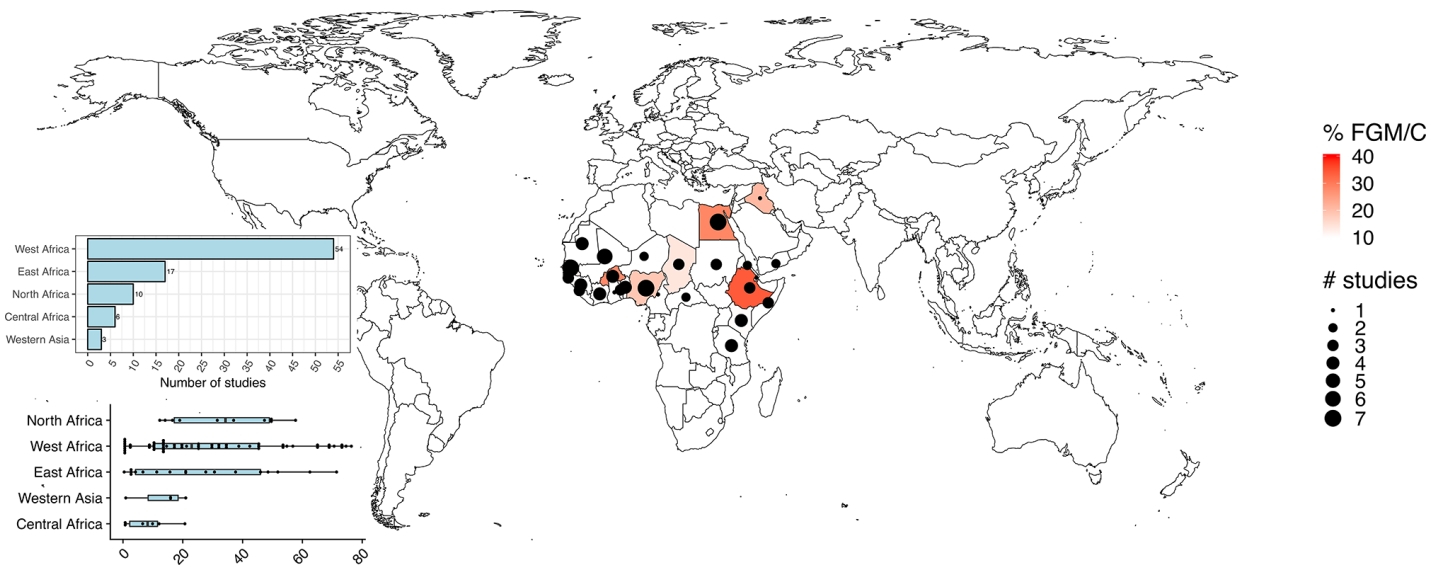

Figure 1 Location of included studies. FGM/C, female genital mutilation or cutting. 
Table 2 Regional trends in percentage of circumcised girls aged 0-14

\begin{tabular}{lcllll}
\hline Region & Surveys $(\mathbf{n})$ & Period & Start & End & $\begin{array}{l}\text { Percentage } \\
\text { relative changes changes: AAPC (95\% Cl) }\end{array}$ \\
\cline { 3 - 4 } Central Africa & 4 & 2004 & 2015 & -0.081 & $+0.2(-0.7$ to +1.0$)$ \\
East Africa & 13 & 1995 & 2014 & -7.87 & $-7.3(-7.5$ to -7.1$)$ \\
North Africa & 9 & 1990 & 2015 & -3.092 & $-4.4(-4.5$ to -4.3$)$ \\
West Africa & 17 & 1996 & 2017 & -1.903 & $-3.0(-3.1$ to -2.9$)$ \\
Western Asia & 3 & 1997 & 2013 & 0.94 & $+13.7(+12.3$ to +15.0$)$ \\
\hline
\end{tabular}

AAPC, average annual percentage change.

per year from 1995 to 2014. By contrast, the decline in prevalence has been much slower in North Africa (trend $=-4.4 \%, 95 \% \mathrm{CI}-4.5 \%$ to $-4.3 \%$ ) and West Africa (trend $=-3.0 \%, 95 \%$ CI $-3.1 \%$ to $-2.9 \%$ ). However, in Western Asia, between 1997 and 2015, the prevalence of FGM/C among children aged 0-14 increased by $+19.2 \%$ $(95 \% \mathrm{CI}+16.9 \%$ to $+21.7 \%)$ per year. A non-statistically significant uptrend was also observed in Central Africa (trend $=+0.2 \%, 95 \% \mathrm{CI}-0.7 \%$ to $+1.0 \%$ ).

\section{DISCUSSION}

\section{Main findings}

We found that the prevalence of FGM/C among children varied greatly between countries and regions and also within countries over the survey periods. Specifically, West, East and North African countries, including Mali, Mauritania, Gambia, Guinea, Djibouti and Sudan, have pooled prevalence estimates well over $40 \%$. These rates may be consistent with the influence of different predictors, including geographical mobility, socioeconomic and cultural factors acting at individual, family and tertiary levels. ${ }^{26}$ Our study found a huge and significant decline in the prevalence of FGM/C among children aged 0-14 years across countries and regions. This current evidence points towards the success of the national and international investment and policy intervention in the last three decades. ${ }^{27}$ One possible explanation in the decrease of FGM/C among young girls (0-14 years) could be the legal ban currently in place in most of these countries, where strong cultural and traditional influence may have acted as an effective deterrent as seen in the decline among these cohorts. ${ }^{28}$

Although there is clear evidence of significant decline in the prevalence among the population studied here (children aged 0-14 years old), the FGM/C risk factors still prevail, which potentially heightens the likelihood of reverse trend in some countries. These risk factors include lack of, or poor, education, poverty, gendered cultural forces, weak social fitness and continued perception of FGM/C as a potential marriage market activity. $^{29-34}$ The health and socioeconomic consequences of FGM/C coupled with its risk factors may mean

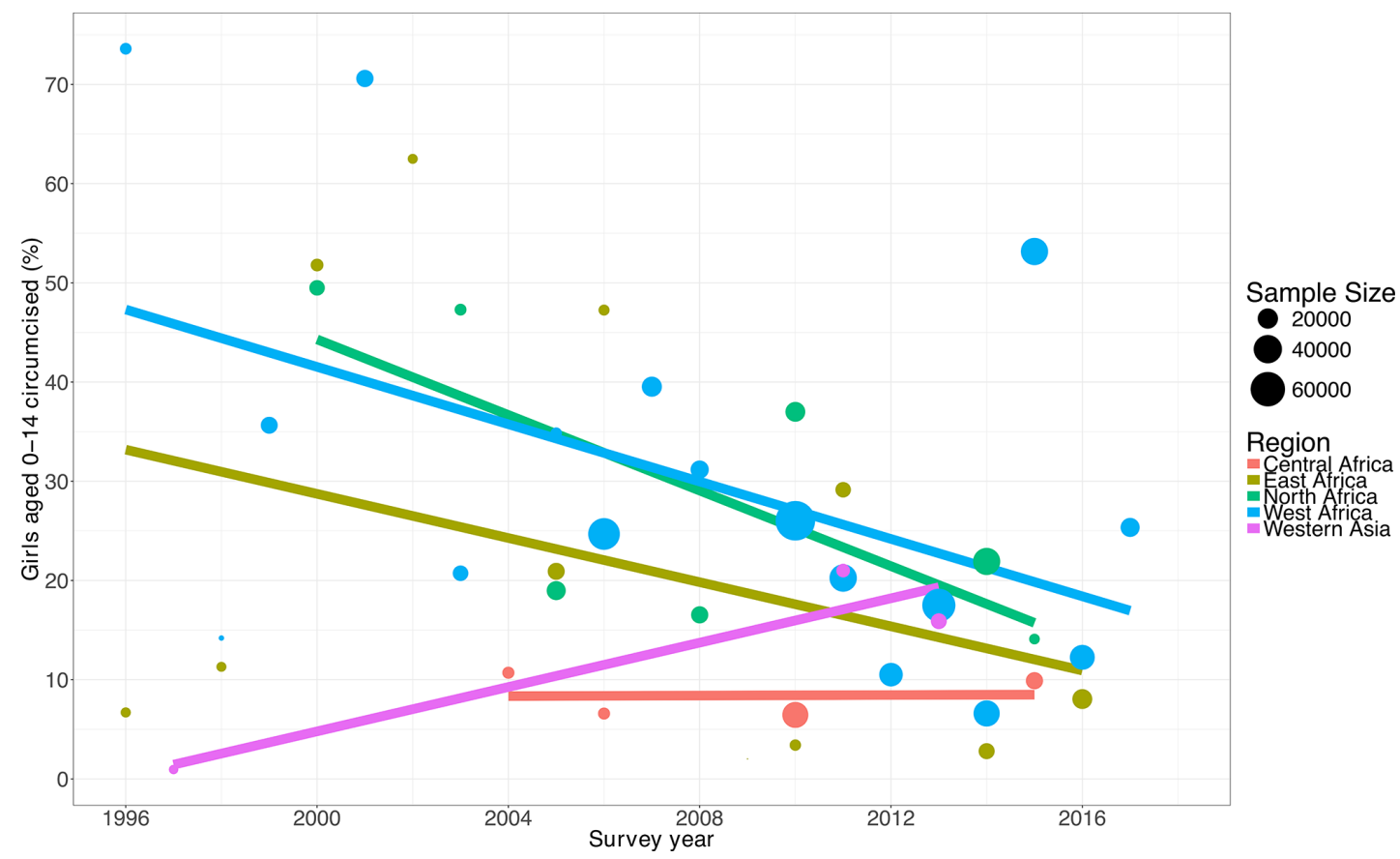

Figure 2 Secular trends in prevalence of female genital mutilation or cutting among children. 
growing underinvestment and gross domestic product losses, which itself reflects increased loss in productivity and reduced labour efficiency in LMICs. Moreover, those regions and subregions showing high prevalence of FGM/C should be the focus of renewed government and donors' policy efforts. If the goal of public policy is to ensure that the practice is eliminated, further efforts and interventions as well as service planning are urgently needed. This package of comprehensive intervention could include legislation, advocacy, education and multimedia communication, in order to come up with more culturally sensitive and community-engaging strategies such as forging partnership with religious and community leaders, youths and health workers to drive the practice downward. ${ }^{16} 1835-41$

\section{Strengths and limitations}

There are a number of caveats to be considered when interpreting these results. The main limitation of the study is the risk of reporting bias, as with similar studies of this kind; we were unable to deal with bias associated with self-reports. ${ }^{42}$ This is particularly common in Africa, where there are multiple burden of public health issues including illiteracy, poverty, and communicable and non-communicable diseases. ${ }^{43} \mathrm{It}$ is possible that responses to culturally sensitive issues such as FGM/C will have distorted the findings; it may be under-reported. In fact, a recent body of evidence suggests that under-reporting of FGM/C cases could occur. ${ }^{8}$ Such an under-reporting may be due to fear that the new legislation banning the practice across many jurisdictions would lead to prosecution of relatives if disclosure was made about their FGM/C status. Another limitation is that we did not consider all the study-level participants' characteristics, which may have further increased the knowledge of the dynamics of FGM/C practices.

Despite these limitations, the strengths of the study are significant. It is a large, population-based study with national coverage. In addition, the DHS data are widely perceived to be of high quality, as they were based on sound sampling methodology with high response rate. The DHS also adheres to stringent ethical rules in the collection of sensitive topics such as FGM/C. Another important strength of this study is the number of included countries, and geographical and socioeconomic diversities constitute a good yardstick for the region and help to strengthen the findings from the study.

\section{CONCLUSIONS}

The prevalence of FGM/C among children aged 0-14 years varied greatly between countries and regions and also within countries over the survey periods. There is evidence of huge and significant decline in the prevalence of $\mathrm{FGM} / \mathrm{C}$ among children across countries and regions. There is a need to sustain comprehensive intervention efforts. In addition, further targeted culturally sensitive policy intervention and other effective strategies for preventing FGM/C should be a major public health priority in countries and regions still showing high prevalence of FGM/C among children, where the practice is still pervasive.

\section{Author affiliations}

${ }^{1}$ Department of Mathematics, Physics and Electrical Engineering, Faculty of Engineering and Environment, Northumbria University, Newcastle upon Tyne, UK ${ }^{2}$ Division of Epidemiology and Biostatistics, University of the Witwatersrand, School of Public Health, Johannesburg, South Africa

${ }^{3}$ British Association of Dermatologists, Willan House, Fitzroy Square, London, UK ${ }^{4}$ Warwick-Centre for Applied Health Research and Delivery (WCAHRD), Warwick Medical School, University of Warwick, Coventry, UK

Contributors N-BK conceived of and designed the study, interpreted the results, and was involved in conducting the literature review and drafting the article. MCE conducted the data analysis, and was involved in conducting the literature review, interpreting the results and drafting the article. OAU was involved in conducting the literature review, interpreting the results and drafting the article. PK was involved in interpreting the results and drafting the article. All authors performed critical revisions for important intellectual content and read and approved the article.

Funding Funding for this work was provided by UK Aid and the UK Government through the Department for International Development-funded project, 'Evidence to End FGM/C: Research to Help Girls and Women Thrive', coordinated by Population Council. N-B K recieved partial support through the DELTAS Africa Initiative SSACAB [grant\#DEL-15-005]. The DELTAS Africa Initiative is an independent funding scheme ofthe African Academy of Sciences (AAS)'s Alliance for Accelerating Excellence inScience in Africa (AESA) and supported by the New Partnership for Africa'sDevelopment Planning and Coordinating Agency (NEPAD Agency) with funding fromthe Wellcome Trust [grant \#107754/Z/15/Z] and the UK government. The views expressed in this publication are those of the author(s) and not necessarilythose of AAS, NEPAD Agency, Wellcome Trust or the UK government. OAU is supported by the National Institute for Health Research using Official Development Assistance (ODA) funding.

Disclaimer The views expressed in this publication are those of the authors and not necessarily those of the AAS, NEPAD Agency, Wellcome Trust, the UK Government, NHS, the National Institute for Health Research, or the Department of Health and Social Care.

Competing interests None declared.

Patient consent Not required.

Provenance and peer review Not commissioned; externally peer reviewed.

Data sharing statement All data are open access data.

Open access This is an open access article distributed in accordance with the Creative Commons Attribution Non Commercial (CC BY-NC 4.0) license, which permits others to distribute, remix, adapt, build upon this work non-commercially, and license their derivative works on different terms, provided the original work is properly cited, appropriate credit is given, any changes made indicated, and the use is non-commercial. See: http://creativecommons.org/licenses/by-nc/4.0/

\section{REFERENCES}

1. UNICEF, 2018. At least 200 million girls and women alive today living in 30 countries have undergone FGM. https://data.unicef.org/topic/ child-protection/female-genital-mutilation (accessed 20 Feb 2018).

2. UNICEF. Female genital mutilation/cutting: a global concern. New York: UNICEF, 2016: 1-4.

3. Leye E, Mergaert L, Arnaut C, et al. Towards a better estimation of prevalence of female genital mutilation in the European Union: interpreting existing evidence in all EU Member States. Genus 2014;70:99-121.

4. Alison Macfarlane B, Stat F. Female genital mutilation in England and Wales: updated statistical estimates of the numbers of affected women living in England and Wales and girls at risk Interim report on provisional estimates. Northampton Square. London: City University London, 2014:1-24.

5. Macfarlane A, Dorkenoo E. Prevalence of female genital mutilation in England and Wales: national and local estimates. London, London: City University, 2015:1-32. 
6. Johnsdotter S, Essén B. Cultural change after migration: circumcision of girls in Western migrant communities. Best Pract Res Clin Obstet Gynaecol 2016;32:15-25.

7. Serour GI. Medicalization of female genital mutilation/cutting. African Journal of Urology 2013;19:145-9.

8. Jackson EF, Akweongo P, Sakeah E, et al. Inconsistent reporting of female genital cutting status in northern Ghana: explanatory factors and analytical consequences. Stud Fam Plann 2003;34:200-10.

9. Yoder PS, Wang S, Johansen E. Estimates of female genital mutilation/cutting in 27 African countries and Yemen. Stud Fam Plann 2013;44:189-204.

10. Mpinga EK, Macias A, Hasselgard-Rowe J, et al. Female genital mutilation: a systematic review of research on its economic and social impacts across four decades. Glob Health Action 2016;9:31489.

11. Banks $E$, Meirik $\mathrm{O}, \mathrm{WHO}$ study group on female genital mutilation and obstetric outcome. Female genital mutilation and obstetric outcome: WHO collaborative prospective study in six African countries. Lancet 2006;367:1835-41.

12. Berg RC, Odgaard-Jensen J, Fretheim A, et al. An updated systematic review and meta-analysis of the obstetric consequences of female genital mutilation/cutting. Obstet Gynecol Int 2014;2014:1-

13. Meirik O, Banks E, Farley T, et al. Female genital mutilation and obstetric outcomes: flawed systematic review and meta-analysis does not accurately reflect the available evidence. Obstet Gynecol Int 2014;2014:1-.

14. WHO. Eliminating female genital mutilation: an interagency statement-OHCHR, UNAIDS, UNDP, UNECA, UNESCO, UNFPA, UNHCR, UNICEF, UNIFEM. Geneva: World Health Organization, 2008.

15. Johansen REB, Diop NJ, Laverack G, et al. What works and what does not: a discussion of popular approaches for the abandonment of female genital mutilation. Obstet Gynecol Int 2013;2013:1-.

16. Berg RC, Denison E. Interventions to reduce the prevalence of female genital mutilation/cutting in African countries. Campbell Syst Rev 2012;8:1-156.

17. Gupta GR. Female genital mutilation/cutting: a statistical overview and exploration ofthe dynamics of change. Reprod Health Matters 2013:184-90.

18. Shell-Duncan B, Naik R, Feldman-Jacobs C. A state-of-the-art synthesis on female genital mutilation/cutting. What do we know now? New York: Population Council, 2016: 1-36.

19. Ezejimofor MC, Uthman O, Chen Y-F. Magnitude and pattern of hypertension in the Niger Delta: a systematic review and metaanalysis of community-based studies. J Glob Health 2001;8:1.

20. Miller JJ. The inverse of the Freeman-Tukey double arcsine transformation. The American Statistician 1978;32:138-38.

21. DerSimonian R, Laird N. Meta-analysis in clinical trials. Control Clin Trials 1986;7:177-88.

22. Higgins JP, Thompson SG, Deeks JJ, et al. Measuring inconsistency in meta-analyses. BMJ 2003;327:557-60.

23. Stroup DF, Berlin JA, Morton SC, et al. Meta-analysis of observational studies in epidemiology: a proposal for reporting Jama 2000;283:2008-12.

24. Ezejimofor MC, Chen Y-F, Kandala N-B, et al. Stroke survivors in low- and middle-income countries: a meta-analysis of prevalence and secular trends. J Neurol Sci 2016;364:68-76.

25. Lesko CR, Cole SR, Zinski A, et al. A systematic review and meta-regression of temporal trends in adult CD4(+) cel count at presentation to HIV care, 1992-2011. Clin Infect Dis 2013;57:1027-37.

26. Mberu BU, Pongou R, 2010. Nigeria: Multiple forms of mobility in Africa's demographic giant. Migration information source. http:// www.migrationinformation.org/Profiles/display.Cfm (accessed 29 Mar 2018).

27. Ajiye S. Achievements of millennium development goals in Nigeria: a critical examination. Int Affairs Glob Strategy 2014;25:24-36.

28. El-Zanaty FH, Hussein A, Sayed H, et al. Egypt Demographic and Health Survey 1992. Cairo: Egypt: National Population Council, 1996:1-346.

29. Karmaker B, Kandala NB, Chung D, et al. Factors associated with female genital mutilation in Burkina Faso and its policy implications. Int J Equity Health 2011;10:20.

30. Demographic and Health Surveys. Health survey 1989/1990: department of Statistics, ministry of economic and national planning, Khartoum, Sudan. Columbia, Maryland USA: Institute for Resource Development/Macro International, 1991.

31. World Health Organization. Understanding and addressing violence against women: intimate partner violence. World Health Organization, 2012: 1-8.

32. Dawkins R. In: Krebs JR, Davies NB, eds. Behavioral ecology: an evolutionary approach. Oxford, England: Blackwell Scientific Publications, 1978: 282-309.

33. Nettle D, Gibson MA, Lawson DW, et al. Human behavioral ecology: current research and future prospects. Behavioral Ecology 2013;24:1031-40.

34. Howard JA, Gibson MA. Frequency-dependent female genital cutting behaviour confers evolutionary fitness benefits. Nat Ecol Evol 2017;1:49.

35. Berg RC, Denison EM. A realist synthesis of controlled studies to determine the effectiveness of interventions to prevent genital cutting of girls. Paediatr Int Child Health 2013;33:322-33.

36. Easton P, Miles R, Monkman K. Final report on the evaluation of the Tostan/IEP village empowerment program pilot project in the Republic of Mali. Tallahassee, Florida: Florida State University, 2002.

37. Mounir GM, Mahdy NH, Fatohy IM. Impact of health education program about reproductive health on knowledge and attitude of female Alexandria University students. J Egypt Public Health Assoc 2003;78:433-66

38. Chege J, Askew I, Igras S. Testing the effectiveness of integrating community-based approaches for encouraging abandonment of female genital cutting into CARE's reproductive health programs in Ethiopia and Kenya. Washington, DC: Population Council, 2004.

39. Babalola S, Brasington A, Agbasimalo A, et al. Impact of a communication programme on female genital cutting in eastern Nigeria. Trop Med Int Health 2006;11:1594-603.

40. Ako MA, Akweongo P. The limited effectiveness of legislation against female genital mutilation and the role of community beliefs in Upper East Region, Ghana. Reprod Health Matters 2009;17:47-54.

41. Diop NJ, Askew I. The effectiveness of a community-based education program on abandoning female genital mutilation/cutting in Senegal. Stud Fam Plann 2009;40:307-18.

42. Elmusharaf S, Elhadi N, Almroth L. Reliability of self reported form of female genital mutilation and WHO classification: cross sectional study. BMJ 2006;333:124.

43. Klouman E, Manongi R, Klepp KI. Self-reported and observed female genital cutting in rural Tanzania: associated demographic factors, HIV and sexually transmitted infections. Trop Med Int Health 2005;10:105-15. 